\title{
O Protocolo de Olivos para a Solução de Controvérsias no Mercosul: um Avanço Institucional?!
}

\author{
Alessandra Lehmen ${ }^{2}$
}

\begin{abstract}
Sumário: Introdução. Parte I - O novo sistema de solução de controvérsias no Mercosul: a) Principais inovações; b) Algumas deficiências não superadas pelo Protocolo de Olivos. Parte II - O Protocolo de Olivos e o processo de integração: a) Tribunal Permanente de Recursos, soberania e supranacionalidade; b) A opção vinculante da regra de eleição de foro prevista no art. $1^{\circ}, 2$, do Protocolo de Olivos. Conclusão. Bibliografia.
\end{abstract}

\section{INTRODUÇÃO}

O presente trabalho tem por objeto tratar das inovaçōes trazidas ao sistema de solução de controvérsias do Mercosul na esteira do ainda recente "Protocolo de Olivos para a Solução de Controvérsias no Mercosul" (dotavante denominado PO), aprovado en 18 de fevereiro de 2002 na cidade que dá nome ao documento. Cumpre frisar, de pronto, que a efetiva entrada em vigor do Tratado é deveras recente: nos termos do artigo 52 do $\mathrm{PO}$, tal se deu, no âmbito internacional, no dia $1^{\circ}$ de janeiro

\footnotetext{
Trabalho apresentado no Programa de Pós-graduaçăo em Direito - Mestrado ern Direito da Universidade Federal do Rio Grande do Sul em 09 de maio de 2004 , na disciplina intitulada "Integração Regional e Globalização", ministrada pela Prof." Dra. Martha Lucía Olivar Jimenez.

${ }^{2}$ A autora é advogada, sócia do escritório Castro, Barros, Sobral, Gomes. Graduou se em Direito pela UFRGS, é pós-graduada em Direito da Empresa e da Lconomia pela Fundação Getúlio Vargas e Mestranda em Direito pela UFRGS. Freqüentou o Programa de Negociação de Harvard e a Academia de Direito Americano e Comparado promovida pelo Instituto de Direito Internacional e Comparado ("Institute for International and Comparative Law") de Dallas, Texas, de cujo Conselho Consultivo é membro.
} 
de 2003, ou seja, trinta dias após o depósito da última ratificação (pelo Brasil, em 02 de dezembro de 2003$)^{3}$. Acrescente-se a tal comentário a informação de que, no Brasil, a introdução do $\mathrm{PO}$ no ordenamento juridico interno deu-se através do Decreto $\mathrm{n}^{\circ} 4.982$, de 09 de fevereiro do corrente ano. Note-se, ainda, que o Regulamento do PO, veiculado através da Decisão $37 / 2003$ do Conselho do Mercado Comum, foi firmado em Montevidéu em 15 de dezembro de 2003. Trata-se, indubitavelmente, de tema de acentuada relevância, reforçada pela recentissima entrada em vigor, tanto nos planos internacional quanto interno, do $P O$. Ademais, ainda que não se pretenda, com estes sucintos comentários, abordar o assunto em toda a sua profundidade ou amplitude, entendemos que o tema tem recebido escassa atenção por parte da doutrina, o que denota ser oportuno, segundo cremos, o estudo da matéria.

Ainda a título introdutório, deve-se informar desde logo que, além da natural tarefa de tecer comentários críticos às inovações efetuadas pelo $\mathrm{PO}$, pretendese analisar o papel do aludido documento com relação ao arranjo institucional do Mercosul. Com efeito, tem-se o objetivo de identificar se, sob esse prisma, será adequado afirmar que $\mathrm{PO}$ trouxe em seu bojo a superação das críticas efetuadas à freqüentemente apontada "indecisão vocacional" do bloco - entre os modelos de cooperação econômica, de integração e comunitário -, bem como, por via de conseqüência, ao arcabouço de instituições que the dá conformação (naturalmente incluído, pois, seu sistema de soluçăo de controvérsias).

Delineado, ainda que brevemente, o escopo do presente trabalho, cumpre, antes de adentrar propriamente o tema da exposição, tecer sucintos comentários para que se tenha em mente o pano de fundo sobre o qual o PO operou alterações - ou deixou de fazê-lo -, a saber, o panorama normativo que o antecedeu no âmbito da solução de controvérsias no Mercosul.

O anterior sistema de solução de controvérsias se assentava no Protocolo de Brasília, emendado por disposições do Protocolo de Ouro Preto e seu Anexo, e previa, basicamente, duas modalidades de procedimento: o político ou diplomático e o jurídico. $O$ processo diplomático revelava-se mais bem elaborado, ressentindo-se o jurídico de aperfeiçoamento. Nesse contexto, foi concluído, em 2002, o PO.

Note-se que o PO, a partir de sua entrada em vigor, derrogou o Protocolo de Brasillia, bem como seu anexo, aprovado pela decisão CMC 17/98. Entretanto,

\footnotetext{
${ }^{3}$ Nota-se que o PO, ao dispor em tal sentido, afastou a necessidade de notificação dos Estados Partes pela Secretaria Administrativa do Mercosul.
} 
este continua aplicável às controvérsias que se tenham iniciado sob a sua vigência ${ }^{4}$. Ademais, continuam em vigor o Protocolo de Ouro Preto e seu anexo, eas remissöes nesses existentes ao Protocolo de Brasilia entenden-se remetidas, no que corresponda, ao $\mathrm{PO}^{5}$

É indispensável assinalar, ainda, que, mesmo após o PO, é o sistema de solução de controvérsias do Mercosul ainda provisório, havendo sido estabelecido como marco para a criação de um sistema definitivo o ano de 2006.

Assim, abordado em linhas gerais, apenas para efeito de referência e objetivando maior clareza, o arcabouço normativo que precedeı o $\mathrm{PO}$, cumpre anotar que a primeira parte do trabalho visa expor as principais inovações introduzidas por dito Protocolo no que tange à solução de controvérsias no Mercosul, buscando analisar criticamente os avanços procedimentais e, com igual ênfase, aqueles temas já identificados como críticos na vigência dos Protocolos de Brasília e Ouro Preto e dos quais o PO absteve-se de tratar.

Em seguida, tha segunda parte da exposição, analisaremos mais detidamente as implicações institucionais acarretadas pelo PO, dedicando-nos à tentativa de, primeiramente, avaliar se seria ou não adequado afirmar que as inovações, em especial a criação do Tribunal Permanente de Recursos, contêtm em sì o getme da supranacionalidade; e, por fin, avaliando as implicaçôes, para a estabilidade do esquema regional, da opção vinculante contida na regra de eleição de foro do art. $1^{\circ}, 2$, do PO.

\section{PARTE I - SOLUÇÃO DE CONTROVÉRSIAS NO MERCOSUL APÓS O PROTOCOLO DE OLIVOS}

\section{a) Principais inovações}

A criação do Tribunal Permanente de Recursos

O Tribunal Permanente de Recursos (doravante chamado TPR, e que setá analisado mais detidamente no item a da Segunda parte, infra) foi, sem dúvida, a inovação mais relevante introduzida pelo PO, na medida em que, justamente por tratar-se de um órgão permanente (por oposição aos Tribunais Arbitrais ad boc, que são transitórios), poderá transformar-se no agente de interpretação uniforme no seio do Mercosul. Com efeito, a freqüentemente criticada ausência de um órgão permanente (e, portanto, a ausência de um corpus de decisões que possa garantir aos operadores

\footnotetext{
${ }^{4}$ Art. 55, item 2.

${ }^{5}$ Art. 55 , item 3 .
} 
do sistema maior previsibilidade quanto ao funcionamento deste e, pois, maiores estabilidade e segurança jurídica), parece superada, ao menos potencialmente, como advento do TPR.

Além da questão da necessidade de criação de um corpo uniforme de decisões do Mercosul, também no que diz respeito à possibilidade de revisão há mudanças significativas, uma vez que o novo sistema consagra duas instâncias, a saber, os Tribunais Arbitrais al boce o novo TPR, que tem a atribuição de tevisar a aplicação das "questões de direito" e das "interpretações juridicas" efetuadas pelos Tribunais ad boc (o recurso de revisão é previsto pelo art. 17 do PO).

Embora nos pareça evidentemente louvável a criação de um órgão de revisão, deve-se reconhecer, por outro lado, que a possibilidade de acesso direto ao TPR, se assim acordarem as partes, introduzida pelo art. 23 do $\mathrm{PO}$, acaba por minimizar o efeito prático de tal previsão. ${ }^{6}$ Resultam da criticada norma dois possíveis efeitos, ambos indesejáveis no âmbito da integração: a supressão da possibilidade de revisão e o esvaziamento da competência dos Tribunais Arbitrais ad boc.

Além disso, o espírito do duplo grau resta sobremaneira limitado, a nosso ver, pela regra do item 3 do art. 17 do $\mathrm{PO}$, que estabelece que, sendo olaudo arbitral emitido com base em princípios de eqüidade (ex aquo et bono), não será este suscetivel de recurso de revisão.

\section{Opiniões consultivas}

Outra inovação, que diz respeito às atribuições do TPR, está contida no art. $3^{\circ}$ do $\mathrm{PO}$, que prevê a possibilidade de o Conselho Mercado Comum "estabelecer mecanismos relativos à solicitacáa de opiniôes consultivas ao Tribunal Permanente de Revisãa".

Não há maiores esclarecimentos, na letra do $\mathrm{PO}$, acerca do procedimento para a realização de tais consultas, tampouco com relação à natureza destas, o que lcvou a indagações ${ }^{7}$ acerca de sua possível equiparação ao "reenvio prejudicial", de

\footnotetext{
"Para DANCINO, Bettina e DEL RÍO, Marina Garcia "La nueva justicia en el Mercosur" artigo publicado em $01 / 04 / 2002$ no site www mujeresdempresa.com/comercio/ comercio020401.htm, consultado em 11/05/2004), o mencionado artigo 23 "desvirtua la importancia y la transcendencia del Tribunal de Revisión Permanente, que como su nombre lo indica fue concebido para reveer un laudo emanado por otro Tribunal y no para entender en forma originaria."

${ }^{7}$ Com efeito, CHOER MORAES (Henrique, "O novo sistema jurisdicional do Mercosu?

- Um primeiro olhar sobre o Protocolo de Olivos", in Revista de Direito Constitucional e Internacional, São Paulo, 39, abril-junho de 2002, p. 63) anota, a esse respeito, que "Apesar de demandar implenentação, a disposição não deixa de suscitar questionamentos: o que se pretende com essa competência consultiva? Instalar un sistema de reenvio prejudicial no Mercosul?"
} 
efeitos vinculantes. Entretanto, o Regulamento do $\mathrm{PO}$, em seu art. 11 , veio a dirimir quaisquer dúvidas a esse respeito, eis que dispõe expressamente que "As opiniões consultivas emitidas pelo TPR näo serão vinculantes nem obrigatórias". Parecenos, aliás, que tal disposição vem a penas a confirmar a única interpretação do texto do $P O$ que se afiguraria condizente com o modelo intergovernamental adotado pelo Mercosul, no qual a atribuição de efeitos vinculantes a dita opinião consultiva claramente esbarraria. Com efeito, embora seja reconhecidamente necessária a criação de mecanismos de colaboração entre os juízes nacionais e os órgãos do bloco, $\mathrm{cm}$ especial aqueles dedicados à solução de controvérsias, não há aplicabilidade direta de nornas no âmbito interno. Assim, resulta logicamente inviável pretender que a consulta vincule diretamente o órgão nacional, jurisdicional ou de outra natureza, bem como os particulares que a tal órgão tenha confiado uma controvérsia.

\section{Eleição de foro}

O art. $1^{\circ}, 2$, do PO estabeleceu a possibilidade de submissão de conflitos a outros foros, tais como a OMC ou outros esquemas preferenciais de comércio a que pertençam os Estados Partes. O exercício de tal opção, todavia, por conta do referido dispositivo, tem o efeito de adstringir os Estados Parte ao foro eleito, excluindo-se qualquer dos demais.

Os efcitos de tal opção vinculante scrão analisados em maiores detalhes no item $b$ da segunda parte do presente trabalho, mas parece relevante apontar, desde logo, que tal disposição tem por objetivo, presumivelmente ${ }^{\sharp}$, evitar a repetição de situações tais como aquela envolvendo o conflito entre Brasil e Argentina sobre a questão dos frangos eviscerados, em que, não havendo o primeiro logrado êxito junto ao Tribunal ad boc do Mercosul, reapresentou a questão à $\mathrm{OMC}$ ?

\section{Atuação do Grupo Mercado Comum}

$O$ art. $6^{\circ}$, item 1 , do $\mathrm{PO}$ estabelece que, inexitosas as negociações diretas, $\mathrm{O}$ recurso ao GMC é facultativo, podendo qualquer das partes na controvérsia iniciar diretamente o procedimento arbitral.

Considerando que o Protocolo de Ouro Preto é mantido em vigor pelo PO, podem ainda as controvérsias surgir no âmbito da CCM (que, ademais, vem desenvolvendo uma tarefa importante nesse sentido, concentrando número de

\footnotetext{
"Há menção expressa ao Sistema de Solução de Controvérsias da OMC no art. 1", 4, do Regulamento do $\mathrm{PO}$.

" Controvérsia sobre a "Aplicação de Medidas Antidumping contra a expostação de frangos inteiros, provenientes do Brasil, Resolıção $t^{\circ}$ 574/200 do Ministério da Economia da República Argentina"; laudo emitido em 2 $/ 05 / 01$.
} 
consultas mais significativo que o GMC); a novidade, aqui, é que, impossivel a solução junto a esse órgão, já não é necessátio submetê-la ao GMC. A distinção básica apontada entre a atuação dos referidos órgãos é a de que a CCM, por compatação ao GMC, tende a ser um órgão mais técnico e menos politico ${ }^{10}$,

\section{b) Algumas deficiências não superadas pelo Protocolo de Olivos}

\section{Limitação do objeto da controvérsia}

$\mathrm{OPO}$, ao determinar em seu art. 14, item 1, que o objeto das controvérsias "ficará determinado pelos textos de apresentagão e de resposta apresentados ante o Tribunal Arbitral Ad Hoc", acaba por reeditar a lacuna existente no art. 28 do Protocolo de Brasília e tratada de forma distinta em sucessivos laudos arbitrais. $O$ art. 27,1 , do Regulamento do PO contém dicção similar; no item 2 do citado artigo há determinação de que deverá levar-se em conta o quanto suscitado em etapas anteriores da controvérsia, mas apenas para a parte demandada no caso de esta não haver apresentado resposta perante o Tribunal Arbitral Ad Hoc.

A questão que aqui se ventila é a hipótese de um Estado Parte, quando da apresentação escrita da controvérsia, alargar seu escopo por comparação ao que fora discutido na fase de negociações prévias. A perplexidade que daí decorre é, naturalmente, a de que a admissão de tal possibilidade acabaria por acarretar a eliminação da fase diplomática - ao menos quanto à parcela da controvérsia em que houve inovação -, acessando-se diretamente a fase arbitral. Parece-nos que a interpretação literal da regta de limitação do objeto da controvérsia contida no $\mathrm{PO}$ acabavia por consagrar tal circunstância, o que não nos parece conforme ao espírito do processo de integração.

Fase pós-laudo

Deve-se anotar, também, que o PO, apesar de ter estabelecido, em seu art. 31, a sujeição dos Estados Partes sucumbentes a medidas compensatórias, parecenos que o PO perdeu a oportunidade de regular de forma mais clara tais medidas e sua aplicação, o que resultaria tanto mais relevante em se considerando a necessidade de estabelecer formas efetivas de cumprimento dos laudos arbitrais, em especial dada a força coercitiva das medidas congêneres no âmbito da $\mathrm{OMC}^{\text {"t }}$.

${ }^{10}$ Segundo LABRANO, Roberto Ruiz Díaz (Mercosur, integración y derecho. Buenos Aires, Intercontinental, 1998, p. 554),

"las reclamaciones de los Estados Parte, de la propia Sección Nacional y de los particulares, pueden por tanto ser canalizadas a la comisión de Comercio del Mercosur, que por su composición más técnica podría arrojar un resultado positivo a la reclamación, pero la solución de conflictos y controversias rodeados e impregnados de un sistema de consenso aleja la posibilidad de una adecuada solución jurisdiccional."

1" KLOR, Adriana Dreyzin de, em "El Protocolo de Olivos" (in Curso de Diretto Internacional Contemporâneo, coord. Florisbal de Souza Del'Olmo, Rio de Janeiro, Forense, 2003, p. 27), 


\section{Acesso de particulares ao sistema de solução de controvérsias}

Dentre os pontos criticos sobre os quais o PO silenciou, aquele que, segundo pensamos, compromete de forma mais acentuada a efetividade do sistema de solução de controvérsias do Mercosul diz respeito ao acesso de particulares (pessoas físicas ou jurídicas).

Com efeito, o PO, a despeito dos argumentos em contrário apresentados pela delegação uruguaia, não inovou no que dizz respeito às insatisfatórias regras a esse respeito, permanecendo os particulares sem possibilidade de apresentação direta de uma demanda. Persiste, assim, a necessidade de que o particular seja assistido pelo Estado Parte de que é nacional, se a reclamação dirigida à Seção Nacional do Grupo Mercado Comum ou da Comissão de Comércio do Mercosul for entendida como dotada de condições de procedibilidade.

Assim, vislumbra-se imensas barreiras ao acesso do individuo ao sistema de reparação, mesmo porque, ainda que seja dado prosseguimento ao seu pleito, deverá aquele arcar com custos muitas vezes desproporcionais à sua condição.

Como alternativa, restaria o acesso às vias judiciais nacionais, mas, em se tratando de sistema que consagre o primado do direito interno, ou, ainda, caso se tenha ambos em condições de igualdade e violação do direito do particular repouse, justamente, em norma interna que contrarie o sentido de norma anterior de fonte inrernacional, resta evidente que não logrará êxito.

Ainda mais grave é a constatação de que não há qualquer previsão específica para o caso de ser a violação às normas regionais perpetrada pelo próprio paí de origem do particular lesado. A Seção Nacional do GMC, evidentemente, é um órgão do Mercosul e não do Estado Parte em que se localiza, mas dele depende o particular para que sua reclamação seja encaminhada ao sistema de solução de controvérsias propriamente dito.

Em síntese, verifica-se que o sistema de solução de controvérsias do Mercosul, no que diz respeito ao acesso de particulares, carece de efetividade, o que, obviamente, é pernicioso, pois não se pode perder de vista que, afinal, pretende-se que o individuo tenha inserção plena no panorana da integração. ${ }^{12}$

assinala que "La opción receptada en orden a la elección de foros se relaciona también, con la cuestión del cumplimiento del laudo. Dada la fuerza multilateral de la OMC es más probable - aunque no sea lo deseable, hecho que requerirá ćempo y acomodamiento - que los EP del Mercosur cumpian lo dispuento por un panel de la OMC, que lograr igual resultado bilateralmente dentro del bloque."

12 Frisa BRANCO, Luizella Giardino B., ao comentar o sistema anterior ao PO, em Sistema de solução de controvérsia no Mercosul - Perspectivas para a criação de um modelo institucional permanente (São Paulo, LTr, 1997, p. 167), que "(...) é de suma importância delimitat o âmbito de atuação do tribunal ou sistema que vier a substituir o atual miodelo de soluçăo de controvérsias 


\section{PARTE II - O PROTOCOLO DE OLIVOS E O PROCESSO DE INTEGRAÇÃO}

a) Tribunal Permanente de Recursos, soberania e supranacionalidade

A doutrina pátria e dos demais países-membros tem apontado, de forma maciça ${ }^{13}$, a necessidade, como condição de viabilidade do processo integracionista (ou, antes, da evolução para um modelo comunitátio propriamente dito) de estabelecer-se regras e instituições supranacionais, isto é, através da atribuição de parte da soberania dos Estados ${ }^{14} \mathrm{Na}$ seara da solução de controvérsias, tal argumento tem sido lançado com especial veemência. É justificada a preocupação, eis que afinal não se pode descurar da interpretação que será dada às normas regionais, no âmbito interno, pelos juízes nacionais. Neste aspecto, e conforme vimos acima, uma das críticas direcionadas ao PO é a falta de regulamentação mais explícita do novo mecanismo de consulta. Entretanto, cumpre manter em mente que, ainda que houvesse o PO estabelecido de forma clara a consulta como forma de reenvio prejudicial - isto é, vinculante para o juiz nacional, não como resultado de hierarquia superior do órgão jurisdicional supranacional, mas como resultado natural da atribuição de parcela de soberania dos Estados Partes -, ainda assim, dada a opçăo do Mercosul por um modelo de intergovernamentalidade, necessária seria a reforma constitucional de seus países-membros.

Essa afirmação tem por base o fato de que, nesse, ao contrátio do que ocorre em um sistema supranacional, inexiste aplicabilidade direta das normas regionais em um modelo intergovernamental, de modo que é indispensável cogitar, para a

do MERCOSUL, cuidando para que este contemple acesso direto dos particulares à sua instância, nos casos em que se julgarem afetados por infraçōes a direitos constituidos e resguardados peias normas comuns, por atos ou omissóes llegais dos Estados-membros, das instituiçôes comunitárias e racionais".

${ }^{13}$ Excetuadas algumas vozes no sencido de que a intergovemamentalidade é, efetivamente, o modelo que melhor se adapta às caracteristicas do Mercosul, ao menos neste estágio do processo de integraçăo.

"Segundo RANGEY, Vicente Marotta ("Solução de controvérsias após Ouro Preto", in Contratos internacionais e direito económico no MERCOSUL, org. Paulo Borba Casella. São Paulo, LT.r, 1996, p. 701), "le evidente que neros tribunais arbitrais ad hoc compostos de três membros, não estão $\mathrm{em}$ condiçōes de exercer controle efetivo de legalidade do MERCOSUL e de realizar um sistema orgânico de constante exegese do sistema de integração regional. Não daräa ensejo, sequer, à elaboração de um compus de decisōes que nos assegurem da uniformidade necessária à tarefa de interpretação." VÉRA MARIA JACOB DE FRADERA ("A circulação de modelos jurídicos europeus na América Latina: um entrave à integração econômica no Cone Sul?", p. 20), aponta que "o Mercado Comum cono objetivo econômico da integração só é possivel dentro de um quadro 'comunitátio', onde as diferenças racionais sejam harmonizadas en consideração aos objetivos comuns, onde uma legislação supranacional elabore regras hamonizadoras, com o fito de regular o agir das empresas, dos bancos e dos empresários." 
aplicação das normas regionais, primeiro, da forma constitucionalmente prevista para a vigência, no plano interno, do direito oriundo dos tratados, e, em segundo lugar, do tratamento que o texto fundamental de cada Estado Parte concede à questão da hierarquia entre direito de fonte internacional e direito interno.

Resultam daf duas constatações: com relação ao primeiro ponto, claro está que, dada a opção do Mercosul pela intergovernamentalidade, parece clato que, inobstante surtam as normas tegionais efeitos no âmbito internacional tão logo cumprido os procedimentos próprios de ratificação e subseqüente notificação, quando for o caso, para que as mesmas sejam efetivamente introduzidas no ordenamento interno - o que releva, e muito, para a adequada e efetiva aplicação das normas comunitárias - há que se observar as peculiaridades constitucionais de cada un dos Estados Partes. A segunda ordem de conclusões deriva do fato de que, a não ser que os Estados Partes consagrem de forna clara, em suas leis fundamentais, o primado do direito internacional se confrontado com norma de direito interno, ocorrcrá de forma inexorável, no mais das vezes ${ }^{15}$, a não aplicação daquele.

Especificamente no caso brasileiro, trata-se de seara pantanosa, mas a conclusão geral a que se chega é que, a não ser no caso específico das normas tributárias e com relação a direitos e garantias fundamentais (entendemos que o $5^{\circ}, \$ 2^{\circ 16}$, da Constituição Federal, constitui verdadeira cláusula geral de recepção automática plena dos tratados, ent matéria de direitos e garantias fundamentais), a ausência de norma constitucional específica nesse sentido e a necessidade de seguir-se o procedimento previsto para incotporação do direito de fonte internacional ao ordenamento interno não autorizan qualquer afirmação no sentido do primado do direito internacional.

Ademais, cumpre anotar que o Projeto de Lei Complementar 243/2002, proposto em 05/11/2002 pelo Senador Moreira Mendes, flilia-se claramente à corrente monista com primado do direito interno, conforme de depreende da análise dos dispositivos a seguir citados:

"Dos tratados e leis estrangeiras

Art. 36 - Os tratados internacionais têm o mesmo nível hierárquico da lei ordinária e a ela se equiparam.

is A teoria monista propugnada por KELSEN (apud DOLXNGLR, Jacob. Direito Internacional Privado. Rio de Janeiro, Renovar, 1994, p.82), ao presstpor a existência de un único ordenamento e conseqüentemente aplicar os métodos tradicionais de superação de antinomias, pode eventualmente resultar na consagraçâo da norma de fonte internacional, acaso seja esta posterior ou especial.

${ }^{16}$ "Art. $5^{\circ}-(\ldots) \ 2^{\circ}-$ Os direitos e gatanuias expressos nesta Constituição não excluem outros decorrentes do regine e dos princípios por ela adotados, ou dos tratados internacionais em que a República Federativa do Brasil seja parte". 


\begin{abstract}
Parágrafo único - A plena eficácia dos tratados internacionais é condicionada à sua aprovação administrativa e ratificação mediante decreto.
\end{abstract}

Art. 37 - A noma legal posterior prevalece sobre tratados, convenções e atos internacionais, nos pontos em que se conflitem".

A constituição uruguaia dispõe de forma análoga à brasileira, enquanto que os textos magnos argentino e paraguaio so freram modificações para reconhecer prevalência às normas resultantes do processo de integração sobre o ordenamento interno.

De todo o panorama acima citado, resulta clara a ausência de segurança jurídica e de previsibilidade no âmbito do esquema regional, dai porque, justamente, tem sido largamente preconizada, como forma de superação de tais entraves, a criação de un modelo supranacional.

Na experiência comunitária européia, como é consabido, a tendência é a de que os textos constitucionais incorporem de modo expresso a prevalência dos tratados. No âmbito do Mercosul, a reticência a um modelo supranacional tem sido comumente apontada como fruto de serem os países sul-ameticanos, de modo geral, de tradição nacionalista, e portanto refratários a qualquer solução que envolva transferência (a um órgão supranacional) de parcela de sua soberania. ${ }^{17}$

Com esse pano de fundo, a pergunta que se impõe é a seguinte: será adequado concluir que o PO, ao criar una instância recursal permanente, se tenba aproximado do modelo supranacional?

Diversas circunstâncias merecem atenção ao se formular uma resposta a tal indagação. Em primeiro lugar, é inegável que o sistema de solução de controvérsias é, em última análise, um reflexo do modelo institucional seguido pelo bloco, sabidamente o da intergovernamentalidade. Assim, é naturalmente impróprio, a nosso ver, tratar do aspecto atinente à solução de controvérsias como se fora estanque ${ }^{18}$.

17 ROSA, Luis Fernando Franceschini da, em Mercosul e função judicial, anota, à p. 122, que "Im nosso contexto, a reticência com que os Estados sul-americanos tratân de questóes ligadas à soberania é explicada pelo extremo apego à doutrina americana da não-intervenção e o receio, consciente ou não, de que experiências integrativas moldadas sobre uma base de supranacionaiidade possam retirar desses mesmos Estados sua autodeterminação".

18 KLOR, Adriana Dreyzin de, em Ed Mercosur - Gerador de una nueva fuente de derecho internacional privado (Buenos Aires, Zavalía, 1997, p. 65), assinala que "Los problemas de la integración no dependen solamente de la adopción de una política de aranceles adecuada. El esquema supone toda una gama de cuestiones vinculadas a la base económica en la que se sustenta que exigen ser consideradas en toda su magnirud". Também nesse sentido, anota DELUCA, Santiago (Unión Europea y Mercosur - Los efectos del derecho comunitatio sobre las iegislaciones nacionales, Buenos Aires, Rubinzal-Culzoni, 2003, p. 131) que "(...) en los 
Com efeito, inobstante ser a criação do Tribunal Permanente de Recursos, muito provavelmente, a inovação mais relevante levada a efeito pelo $\mathrm{PO}$, a criação de um tribunal propriamente supranacional é inviabilizada pelo obstáculo de natureza constitucional representado pelas leis fundamentais brasileira e uruguaia.

Além disso, muito embora constitua o TPR un inegável avanço no sentido de conferir maior estabilidade e segurança ao sistema, uma vez que permititá, ao menos em tese, superar o problema de interpretações discrepantes das normas regionais, apontado como decomente, em grande medida, da transitoriedade dos Tribunais Arbitrais ad hoc, suas decisões não são dotadas de efeitos erga omnes, sendo vinculantes apenas para os países que sejam partes na controvérsia.

Considerados todos os aspectos acima citados, nos parece adequado concluir que, muito embora constitua o TPR um inegável avanço para o processo de integração - tanto sob o prisma procedimental quanto institucional, por ser um agente de interpretação uniforme e, ainda, por representar um passo adiante no sentido da despolitização das decisões no âmbito do Mercosul -, não é possivel considerá-1o como un órgão jurisdicional supranacional. Futuramente, se efetuadas as potenciais reformas constitucionais e exercida uma opção clara do bloco no sentido de atribuir parcelas de soberania para criação de um ente supranacional (e convém lembrar que o atual sistema de solução de controvérsias, mesmo após o PO, é, ainda, provisório), seria provável, nessa mesma esreira, a evolução do atual TPR na direção de uma Corte de Justiça do Mercosul propriamente dita.

b) A opção vinculante da regra de eleição de foro prevista no art. $1^{\circ}, 2$, do Protocolo de Olivos

Conforme apontado no item a da primeira parte do presente trabalho, o arr. $1^{\circ}, 2$, do PO estabeleceu regra de eleição de foro dotada do que se poderia qualificar como um mecanismo de prevenção, eis que, como conseqüência da opção exercida, exclui-se a possibilidade de apresentar à controvérsia perante outro dos foros possíveis.

Nesse contexto, duas questões convidam à reflexão: na bipótese - ainda que pouco provável, dados os necessários affectio societatis entre os membros do bloco e respeito à boa-fé na aplicacăo e interpretafão dos tratados - de um Estado Parte que näo haja alcancado êxito através dos mecanismos de solufäo de

procesos de integración los procedimientos la solución de controversias y la estructura institucional para su resolución se deben adecuar al estado de avance del proceso, constituyendo, a su vez, causa y efecto de esa evolución." 
controvérsias do Mercosul reapresentar a questão junto à $O M C$ ou a outros esquemas preferenciais de coméricio a que pertenca, será a noma do Protocolo de Olivos oponivel a esses últimos entes? Ademais, conterá tal disposigão o germe do esuaziamento do sistema de solufão de controvérsias do Mercosul, en especial considerado o alto grau de êxito das controvérsias submetidas pelo Brasil à $\mathrm{OMC}^{19}$ ?

No tocante à primeira questão - que, en princípio, nos parece apenas hipotética, pelos motivos apontados no parágrafo anterior -, a admitir-se tal citcunstância, temos que o Estado Parte que decidisse derivar do sistema de solução de controvérsias do Mercosul depois de haver por este optado somente poderia sofrer sanções no âmbito do bloco da integração (mais especificamente, aquelas previstas para os casos de descumprimento de laudos arbitrais), una vez que somente com dificuldade poder-se-ia vislumbrar a oponibilidade da regra de prevenção do PO no âmbito multilateral ou de outros blocos a que também pertençam as partes envolvidas na controvérsia.

Com cfeito, tal vinculação só seria possivel lançando mão de interpretação no sentido de que as regras dos órgãos multilaterais, embora não prevejam tal possibilidade, tampouco a excluem, e esta seria admissivel pelo fato de a norma regional ser, em última análise, de cujo internacional, facultando-se a sua adoção por outros entes que não o bloco de integração da qual esta foi emanada. Entretanto, é forçoso reconhecer que a prevalência concreta de uma tal assunção seja remota. Vejase, em semelhante sentido, comentário de GABRIELLE MARCEAU ${ }^{20}$;

"If a dispute is initiated under the DSU, it is extremely doubtful that a DSU panel would give any consideration to a party's request to halt the procedures because similar or related procedures are taking place under a regional arrangement, such as Nafta. A WTO panel would certainly not examine any allegation of a Nafta violation, but it could be asked to examine an alleged WTO violation which would be similar to a Nafta violation."

No tocante à segunda indagação antes formulada, percebem-se con maior nitidez as implicações que esta possa acartetar sob o aspecto institucional. Com efeito, com a introdução da possibilidade de eleição de foro dotada de norma de prevenção, é cabalmente afastada qualquer necessidade de esgotamento de recursos

19 Considerando-se "êxito" como correspondente a resultados sațisfatórios para o Brasil, ainda que não envolvendo vitória total na questão, esse percentual é de cerca de $85 \%$, conforme conferencia proferida pelo diplomata e advogado brasileiro junto à OMC CELSO DE TARSO PEREIRA em 05/05/04, na Universidade Federal do Rio Grande do Sul.

${ }^{20}$ Apud CHOER MORAES, Henrique. Ob. cit, p. 67. 
no âmbito regional antes que se recorra, v.g., a órgão multilateral. A redação do dispositivo, ao consagrar que as controvérsias poderão ser submetidas aos distintos foros "à escolba da parte demandante" (sic), tampouco deixa margem para qualquer interptetação (que se nos afiguratia razoável) no sentido de que as demandas deveriam ser encaminhadas aos distintos foros conforme a sua matéria de fundo prendesse-se a aspectos materiais mais notadamente vinculados às normas de um ou outro esquema, multilateral ou regional.

Assim, dada a consagração a possibilidade de livre eleição, pela parte demandante, de um dentre os possíveis foros da controvérsia, não é dificil vislumbrat o potencial esvaziamento do sistema de solução de controvérsias do Mercosul, com a conseqüente debilitação institucional do bloco. Conforme antecipamos, patece natural que os Estados Partes, por razões eminentemente práticas tais como o conhecimento prévio detido por seu corpo diplonático (e mesmo pelos particulares interessados e seus procuradores) com relação à condução de casos perante outros mecanismos de solução de controvérsias, a previsibilidade e segurança jurídica vislumbradas em tais sistemas (em especial no tocante ao cumprimento dos laudos, já que as medidas com força nultilateral tendem a set naturalmente mais efetivas) e o grau de sucesso historicamente obtido em suas demandas, acabem por exercer a opção por sistemas outros que não o do Mercosul.

A solução para tal potencial problema, segundo entendemos, não é outra senão a consolidação do sistema de solução de controvérsias do Mercosul como um mecanismo apto a proporcionar a seus membros decisões adequadas tanto sob o aspecto da celeridade quanto da segurança jurídica, o que pode passar, conforme já apontado, por uma opção de seus membros, que é antes política do que jurídica, em trilhar o caminho da supranacionalidade (uma vez atingida, naturalmente, a maturação necessária para tanto e não como solução artificial).

Quando se fala em consolidação ou fortalecimento do sistema de solução de controvérsias do Mercosul, entretanto, não se quer preconizar que o bloco deva ceder à tentação, por vezes notada, de tudo regulamentar; pelo contrário; entendemos que essa pretensão, ao menos no que diz respeito ao comércio internacional, não se coaduna com as metas de desenvolvimento econônico, que, afinal, é força motriz relevantíssima ao processo de integração (embora, naturalmente, os objetivos da integração transcendam, em muito, os aspectos comerciais e econômicos). Pelo contrário, por fortalecimento do mecanismo de solução de controvérsias do Mercosul deve-se compreender que, juntamente com a edição de normas claras no tocante às lacunas procedimentais existentes, há que se constituir um corpo de operadores altamente habilitados a aplicar não apenas as normas oriundas do processo de integração, como também a soft law desenvolvida em linha com as exigências e características do comércio internacional, e que ademais é de adoção menos traumática, 
uma vez que ten o mérito de não se imiscuir nos ordenamentos internos ${ }^{21}$. Evitarse-ia, assim, os entraves potencialmente resultantes para o desenvolvimento do comércio internacional dos Estados Partes, en especial dada a proliferação de blocos regionais, bem como a coexistência dos organismos multilaterais, que poderiam emitir regras obrigatórias, mas discrepantes, sobre os diversos aspectos de fundo referentes ao comércio internacional.

Nesse contexto, entendemos oportuno citar artigo de GUIDO ALPA, intitulado "Nouvelles Frontières du Droit des Contrats" $"$, que, descartados alguns excessos no tocante ao desprezo às raízes e valores comuns, ć bastante ilustrativo do que acima se referiu: "(...) é evidente que os processos de barmonizacäa e de unificafäo da disciplina do contrato não passam pelas supostas raizes comuns, nem por valores supostamente comuns, mas sim por resoluçoes práticas e econômicas que unem os juristas na tentativa de favorecer as trocas de bens, de servicos e de capitais. Em outras termos, é o substrato econômico que entrelaga esses processos: é a idéta do contrato enquanto 'vestimenta juridica' da operafáa econômica que une os textos predispostos para a realizafão de uma lingua comum, uma verdadeira koine $\mathrm{e}^{23}$ terminológica, conceitual e normativa".

\section{CONCLUSÃO}

De todo o exposto, pode-se sumarizar as conclusões alcançadas nos seguintes pontos:

1. OPO representa importante inovação na medida em que introduziu, no âmbito dos mecanismos de solução de controvérsias do Mercosul, a figura do Tribunal Permanente de Revisão, que, espera-se, trabalhará no sentido de conferir exegese uniforme às normas regionais, bem como de atribuir maior previsibilidade ao sistema e, pois, maior segurança jurídica aos seus operadores;

\footnotetext{
${ }^{21}$ A decisão proferida em 1968 pela CJCE no caso Firma Malkerci, citada por VÉRA MARIA JACOB DE FRADERA ("Os princípios gerais do Direito Comunitátio", p. 19), estabeleceu que "Les dispositions communautaires pénètrent dans l'otdre juridicue interne sans le secours d'aucune mesure nationale." Tambern SARA G, ZWAR'T ("The new international law of sales: a marriage between socialist, Third World, conmon, and civil law principles", p. 1), referindose especificamente à Convenção de Viena de 1980, afirma que "As no one cares to surrender to foreign legal systems, intentiational traders must sometinies defer to foreign law. The Convention seeks to protect against the vagaries of such foreign law which must be identified, understood, and proven in court. By unifying and codifying an international law of sales, the Convention gives international traders a ready-made fall back position when disagrceing on the applicable law."

$2:$ Ob. cit., p. 1.019 .

${ }^{23}$ Grego biblico, mais simples que a lingua original e utilizado para efeitos de padronizaçăo.
} 
2. $\mathrm{PO}$ perdeu a possibilidade de dispor sobre alguns pontos já considerados críticos sob a vigência dos Protocolos de Brasilia e de Ouro Preto, em especial a viabilização do acesso direto dos particulares - pessoas físicas e jurídicas - aos mecanisnos de solução de controvérșias do Mercosul;

3. O Tribunal Permanente de Recursos, inobstante o fato de consubstanciar um inegável avanço procedimental e institucional, não pode ser considerado um órgão supranacional, eis que a) o modelo adotado pelo bloco é o da intergovernamentalidade c o sistema de solução de controvérsias não pode ser interpretado de forma distinta, a não ser que efetuada uma escolha clara pela supranacionalidade, com a atribuição de parcelas de soberania dos Estados Partes e efetuadas as reformas constitucionais correspondentes; $\mathrm{e}$ b) as decisões do tribunal não têm efeitos erga omnes, limitando-se às partes da controvérsia; e

4. A opção vinculante da regra de eleição de foro prevista no art. $1^{\circ}, 2$, do PO a) não é oponivel aos demais foros possiveis na hipótese de reapresentação, por um Estado Parte, de questão já apreciada no âmbito do sistema de solução de controvérsias do Mercosul, sendo aplicáveis, nesse caso, apenás as sanções previstas no âmbito regional para o descumprimento de laudos arbitrais; e b) contém em seu bojo o potencial esvaziamento do mecanismos de solução de controvérsias do Mercosul em razão da escolha, por razões de ordem eminentemente prática, de outros sistemas, afigurando-se necessário, para evitar-se tal inconveniente e seus reflexos adversos no âmbito do processo de integração, aparelhar o sistema de solução de controvérsias do Mercosul de forma a prestigiar igualmente a celeridade e a segurança juridicas.

\section{BIBLIOGRAFIA}

ALPA, Guido. 'Les nouvelles frontieres du droit des contrats", in Revue Internationale de Droit Comparé, $\pi^{\circ} 4$ (1): 1.015-30, outubro-dezembro de 1998.

BRANCO, Luizella Giardino B.. Sistema de solução de conttovérsia no Mercosul Petspectivas pata a criação de um modelo institucional permanente. São Paulo, LTr, 1997.

DELUCA, Santiago. Unión Europea y Mercosur - Los efectos del derecho comunitario sobre las legislaciones nacionales. Buenos Aites, Rubinzal-Culzoni, 2003.

DOLINGER, Jacob. Direito Internacional Privado. Rio de Janeiro, Renovar, 1994.

FRADERA, Véra Maria Jacob de. "Os principios getais do Direito Comnnitário", in Revista da AJURIS, Porto Alegre: 17-30, novembro de 1998.

. "A circulaça de modelos juridicos europens na América Latina: um entrave à integrafão econônzica no Cone Sul?", in Revista dos Tribunais, São Paulo, 736: 20-39, 1997.

KLLOR, Adriana Dreyzin de. "E/ Protocolo de Olives", in Curso de Direito Internacional Contemporâneo, coord. Florisbal de Souza Del'Oimo. Rio de Janeiro, Forense, 2003, p. $9-50$. 
El Mexcosur - Gerador de una nueva fuente de derecho internacional privado. Buenos Aires, Zavalia, 1997.

LABRANO, Roberto Ruiz. Díaz. Mercosur, integración y derecho. Buenos Aires, Intercontinental, 1998.

MORAES, Henrique Choer. "O novo sistema jurisdicional do Mercosul - Um primeiro olbar sobre o protocolo de Olivos", in Revista de Direito Constitucional e Internacional, Sào Paulo, 39: 57-71, abril-junho de 2002.

PANCINO, Bettina e DEL RÍO, Marina García. 'La nueva justicia en el Mercosur' artigo publicado em 01/04/2002 no site www.mujeresdeempresa.com/comercio/ comercio 020401 htm, consultado en 11/05/2004.

RANGEL, Vicente Marotta. "Solução de controvérsias após Ouro Preto", in Contratos internacionais e direito econômico no MERCOSUL, org. Paulo Borba Casella. São Paulo, LTtr, 1996, p. 692-701.

ROSA, Luis Fernando Franceschini da. Mercosul e função judicial - Realidade e superação. São Paulo, LTr, 1997.

ZWART, Sara G. "The new international law of sales: a marriage between socialist, Tbird World, common, and civil law principles", in North Carolina Journal of International Law and Commercial Reguiation, 13: 109-128, 1988. 